\title{
Photobiomodulation with cluster does not present superior results to placebo in young people with chronic non-specific lumbar pain
}

\author{
Isabela Bohnenberger Escanes ${ }^{1, A-B, D, F}{ }^{\oplus}$, Isabela Cordeiro Baierle ${ }^{1, A-B, D, F}{ }^{\circ}$, Thaise de Assis , $^{1, A-B, D, F}{ }^{\circ}$, \\ Morgana Neves ${ }^{1, A-B, D, F}$, Lucinar Jupir Forner Flores ${ }^{1, A, C, E-F \oplus}$, Gladson Ricardo Flor Bertolini ${ }^{1, A, C, E-F} \oplus$ \\ 1 Universidade Estadual do Oeste do Paraná, Cascavel, Brazil \\ A - Research concept and design, B - Collection and/or assembly of data, C - Data analysis and interpretation, \\ $D$ - Writing the article, E - Critical revision of the article, F- Final approval of article
}

\begin{abstract}
Bohnenberger Escanes I, Cordeiro Baierle I, Thaise de Assis, Neves M, Jupir Forner Flores L, Ricardo Flor Bertolini G. Photobiomodulation with Cluster does not present superior results to placebo in young people with chronic non-specific lumbar pain. J Pre-Clin Clin Res. 2020; 14(4): 107-110. doi: 10.26444/jpccr/130262
\end{abstract}

\section{Abstract}

Introduction and objective. Since the characteristic of chronic non-specific lumbar dysfunction presents a high prevalence and morbidity, and that there are still conflicting results with the use of photobiomodulation, the aim of this study was to analyze the effect of photobiomodulation application in patients with chronic non-specific lombalgy.

Materials and method. A quantitative, experimental, randomized study composed of 21 volunteers randomly separated into two groups: 1) the intervention group (IG), who were given an application of photobiomodulation (LED (617nm $\pm 10 \%$, $1,500 \mathrm{~mW}$ ) and low-level laser therapy $(830 \mathrm{~nm}, 150 \mathrm{~mW}$, beam area $12.57 \mathrm{~mm})$, combined energy of $8.4 \mathrm{~J}$ per area for one minute in four different locations: in regions of greatest pain referred to palpation, on a bilateral basis, area of the applicator $-23,8 \mathrm{~cm} 2)$. 2) the control group (CG), in which the device remained switched-off during therapy. All subjects were evaluated by McGill and Roland Morris questionnaires before and at the end of 6 interventions ( 3 weeks).

Results. For both McGill and Roland Morris total pain rates, there was no inter-group interaction or interaction between evaluation and group $(p>0.05$ ). In the comparison between evaluations (before and after), there was a significant difference $(p<0.001)$.

Conclusions. The use of photobiomodulation in these parameters in young patients with chronic non-specific lombalgy, was not more effective than the placebo for the relief of painful symptoms. Nor did it promote a decrease in the repercussion of lombalgy in the performance of daily activities.

\section{Key words}

laser therapy, low back pain, pain measurement

\section{INTRODUCTION}

Back pain is a prevalent health problem marked by discomfort above the upper gluteal line. It is highly prevalent and it is estimated that about $80 \%$ of adult individuals report at least one episode of this dysfunction at some point in their lives. It directly influences the quality of life of the individual and, as a consequence, impacts on their daily life activities. It is also a frequent cause of morbidity and disability $[1,2]$. Back pain is a musculoskeletal change that may occur due to intrinsic causes: congenital, degenerative, inflammatory, infectious, tumour and mechanical-posture conditions, and extrinsic: excessive efforts and the way of performing activities of daily living, bad postures and psychological factors such as depression and anxiety $[3,4]$.

According to its etiology, it can be classified as specific or non-specific. The specific has a well-defined cause that can be diagnosed, for example, disc herniation [5]. In nonspecific low back pain, although there is no defined cause, the diagnosis is usually associated with musculoskeletal alterations. It is commonly caused by the maintenance of bad postures in daily activities or in the work environment, as

Address for corespondence: Gladson Ricardo Flor Bertolini, Universidade Estadual do Oeste do Paraná, Rua Universitária, 2069, 85819110, Cascavel, Brazil E-mail: gladsonricardo@gmail.com

Received: 09.07.2020; accepted: 06.11.2020; first published: 23.11.2020 well as by excess weight that produces greater pressure on the structures [6,7]. Regarding chronological classification, it is divided into acute - with sudden onset of pain and duration of less than six weeks, subacute - when it is recurrent and lasts from six to twelve weeks, and chronic - when it exceeds 12 weeks and compromises the performance of daily life or work activities [5].

Conservative treatment is usually the initial choice, in which physiotherapeutic modalities are included, among them, joint mobilization and manipulation $[8,9]$, fascial manipulation [10], electrotherapy [11], therapeutic ultrasound [12] and photobiomodulation (PBM) [13]. PBM with the low-level laser therapy (LLLT) associated with a light emitting diode (LED) (Cluster) [8] with therapeutic purposes, such as increased RNA, DNA and ATP synthesis, fibroblast cell proliferation rate and collagen synthesis, increased vascularization and variations in nerve conduction [15-17]. In isolation, LLLT has been shown to be effective, both in clinical and experimental studies in several conditions helping to control pain, reduce the inflammatory process and speed-up tissue repair [18-21], but not without controversial outcomes [22]. Such effects have also been observed for LED therapy [23, 24].

Since the characteristic of chronic non-specific lumbar dysfunction presents high prevalence and morbidity, and that in the use of photobiomodulation there are still conflicting results [25-27], further research is needed in individuals 
with lumbar pain The objective of the present study was to analyze the effect of cluster application (LLLT and LED) in patients with chronic non-specific lumbar pain, evaluating its evolution by means of function questionnaires.

\section{MATERIALS AND METHOD}

A quantitative, experimental, randomized, blinded study by the participant and evaluator, but not by a therapist, conducted at the physical Rehabilitation Center of the Universidade Estadual do Oeste do Paraná (UNIOESTE), in Cascavel, Brazil. The study was approved by the Ethics Committee on Research with Human Beings (CEP) of UNIOESTE (Opinion No. 3,286,703).

The sample consisted of female university students, who had non-specific low back pain and presented the symptoms thast had lasted for more than three months (chronic), recruited on a voluntary basis by invitationsvia social media and posters and characterized as convenient, unintentional. Those with degenerative alterations, systemic disease, infection, neo, including anti-inflammatory or analgesic drugs, were excluded.

This study included 20 students aged $21.3 \pm 1.7$ years, with a mass of $62.0 \pm 11.4 \mathrm{~kg}$, height $-1.62 \pm 0.06 \mathrm{~m}, \mathrm{BMI}-23.6 \pm 4.22$, distributed by means of electronic randomization (with the aid of the resource evailable at http://www.randomizer.org/), in two groups: Control Group (CG, $\mathrm{n}=10)$ and Intervention Group ( $\mathrm{GG}, \mathrm{n}=10)$. Six cluster application session were held, twice a week for a total of 3 weeks. The equipment used was the Fluence LED $(617 \mathrm{~nm} \pm 10 \%, 500 \mathrm{~mW})$ and Laser $(830 \mathrm{~nm}$, $150 \mathrm{~mW}$, beam area $12.57 \mathrm{~mm})$ - HTM, how the two forms of phototherapy were associated, the combined power of $8.4 \mathrm{~J}$ per area, for one minute in four different locations, in regions of greatest pain during palpation, on a bilateral basis, the area of the applicator was $23,8 \mathrm{~cm}^{2}$. For CG individuals, the device remained switched-off, only the time was kept.

Evaluation was performed by applying McGill's pain questionnaire [28] and Roland Morris's disability questionnaire [29], which were applied prior to the first (Ev1) and at the end of the last therapy (Ev2). The choice for McGill's Pain Questionnaire was made to evaluate the sensory-discriminative, affective-emotional and cognitiveevaluation components, which provided quantitative measures of clinical pain that can be treated statistically, as applied in several studies that assess pain symptoms in the most diverse areas with satisfactory reliability [28]. The Roland Morris questionnaire was chosen because it evaluates the repercussion of backache on work activities and daily life. The score is the sum of items which range from zero (no disability) to 24 (severe disability). Values over 14 points indicate physical disability [30].

The results obtained were analyzed by means of descriptive and inferential statistics using the SPSS 20.0 programme, by means of Mixed Generalized Models with post-testing LSD. In all cases, the accepted significance level was 5\%. Hedges' effect size by ' $g$ ' was also used to evaluate the magnitude of the difference between groups, taking into account the following interpretation: $<0.19$ - negligible, $0.20-0.49-$ small, 0.50-0.79 - medium, 0.80-1.29 - large, and $>1.30$ - very large (31.2).

\section{RESULTS}

For the sample size used, it was found that with a difference of 1.5 , standard deviation of 1.0 , the test power was $80 \%$. McGill's pain questionnaire was not observed in any of its variables between groups, nor interaction of factors $(p>0.05)$ having been observed, independent of group, only differences between the first (Ev1) with the second (Ev2) evaluations (Tab. 1).

Table 1. Presentation of the mean and standard deviation values observed for the McGill Pain Questionnaire in the different groups (CG and IG), evaluations (Ev1 and Ev2) and Effect Size (ES)

\begin{tabular}{|c|c|c|c|c|c|}
\hline PAIN INDEX & GROUP & $\mathrm{Ev} 1^{\mathrm{A}}$ & ES & $\mathrm{Ev} 2^{\mathrm{B}}$ & ES \\
\hline \multirow[t]{2}{*}{ Sensorial } & CG & $18.20 \pm 5.75$ & \multirow[t]{2}{*}{-0.931} & $12.70 \pm 5.62$ & \multirow[t]{2}{*}{$-1.03 \mid$} \\
\hline & IG & $17.50 \pm 10.13$ & & $8.90 \pm 6.64$ & \\
\hline \multirow[t]{2}{*}{ Affective } & CG & $2.90 \pm 1.60$ & \multirow[t]{2}{*}{$-0.60 m$} & $1.80 \pm 1.93$ & \multirow[t]{2}{*}{$-0.62 m$} \\
\hline & IG & $2.40 \pm 2.70$ & & $1.00 \pm 1.05$ & \\
\hline \multirow[t]{2}{*}{ Avaliative } & CG & $2.10 \pm 1.28$ & \multirow[t]{2}{*}{$-0.71 m$} & $1.30 \pm 0.823$ & \multirow[t]{2}{*}{-0.901} \\
\hline & IG & $2.00 \pm 1.33$ & & $1.50 \pm 0.71$ & \\
\hline \multirow[t]{2}{*}{ Miscellaneous } & CG & $3.80 \pm 3.12$ & \multirow[t]{2}{*}{$-0.78 m$} & $1.60 \pm 2.22$ & \multirow[t]{2}{*}{$-0.31 \mathrm{~s}$} \\
\hline & IG & $3.50 \pm 3.06$ & & $2.70 \pm 2.83$ & \\
\hline \multirow[t]{2}{*}{ TOTAL } & CG & $27.00 \pm 8.91$ & \multirow[t]{2}{*}{$-1.07 \mid$} & $16.70 \pm 9.45$ & \multirow[t]{2}{*}{$-0.94 I$} \\
\hline & IG & $26.10 \pm 15.96$ & & $14.10 \pm 10.06$ & \\
\hline
\end{tabular}

Different c

Similarly, for the Roland Morris questionnaire there were no differences between the groups or interaction $(\mathrm{p}>0.05)$, only differences between the evaluations $(\mathrm{p}<0.05)$ (Tab. 2).

Table 2. Data for mean and standard deviation in the Roland Morris Questionnaire for the different groups (CG and IG), evaluations (Ev1 and Ev2) and Effect Size (ES)

\begin{tabular}{|c|c|c|c|c|}
\hline GROUP & $\mathrm{Ev} 1^{\mathrm{A}}$ & ES & $\mathrm{Ev}^{\mathrm{B}}$ & ES \\
\hline CG & $5.60 \pm 2.07$ & \multirow[t]{2}{*}{$-1.05 \mathrm{~g}$} & $3.20 \pm 2.30$ & \multirow{2}{*}{$-1.10 \mathrm{~g}$} \\
\hline IG & $6.30 \pm 2.00$ & & $3.50 \pm 2.72$ & \\
\hline
\end{tabular}

Different capital letters show statistical difference between the evaluations. Effect sizes: I- large.

\section{DISCUSSION}

The study aimed to evaluate the use of photobiomodulation in women with chronic non-specific lumbar pain, and it was observed that there were no advantages of its use over both pain and function. Pain is a subjective sensation and its perception results from the complex interaction between different factors, its threshold being variable, being dependent on gender, occupation, cultural attitudes and ethnic group [1]. In addition, the pain has sensory, affective, autonomic and behavioural aspects. Furthermore, the sensation of pain does not necessarily have to be based on any previous experience with it [33].

In this study, when analyzing the data there was significant improvement between the first and second evaluations. It is known that this can occur due to the placebo effect, which occurs by obtaining a positive result by administering the placebo, which has no pharmacological action on the patient's symptoms or diseases, generating a psychological effect, since it does not use the active principle. The expectation of the 
individual that the treatment will be effective causes a change in the performance of the central nervous system, where the areas associated with the perception of pain become less active, while the areas of pain inhibition become more active [34-36].

According to Huang et al. [13], LLLT (Low-level Laser Therapy) generates a reduction of pain in individuals with chronic non-specific lumbar pain, but there is uncertainty regarding improvement in function. In the presented study, both pain characteristics and functional improvement were reduced, since in most variables large effect sizes were achieved, but when compared to the placebo group, the differences were insignificant, demonstrating that the effective treatment did not present superior results.

Contrary to the results observed in the current research, in a study comparing the effect of LLLT $(904 \mathrm{~nm}, 0.04 \mathrm{~W}$, applied in six points totalling 18J, during 10 therapies over four weeks) with therapeutic ultrasound and also using the McGill and Roland-Morris questionnaires, the authors observed that the LLLT showed a reduction in pain intensity and quality, besides functional improvement [12]. Tantawy et al. [27] also observed advantages of LLLT (808nm, 17.05 $\mathrm{J} / \mathrm{cm}^{2}, 30 \mathrm{~J}$ ) associated with exercises, with two sessions per week for eight weeks, compared with therapeutic ultrasound, in the reduction of pain, improvement in functional performance and reduction of disability in individuals with chronic non-specific lumbar pain. Gabel et al. [25], by using photobiomodulation $\left(850\right.$ and $660 \mathrm{~nm}, 3 \mathrm{~J} / \mathrm{cm}^{2}$ at 12 points in the thoracic, lumbar and thigh regions) in individuals with lumbar dysfunction and depression, observed that the association with five physiotherapy sessions was also beneficial as anti-depressant.

Taradaj et al. [26], using both high power (1064nm, $60 \mathrm{~J} /$ $\left.\mathrm{cm}^{2}\right)$ and low power $\left(785 \mathrm{~nm}, 8 \mathrm{~J} / \mathrm{cm}^{2}\right)$ LLLT, did not observe improvements in individuals with degenerative lumbar disc disease, neither in pain nor functional tests, when compared to placebo. This is consistent with the recommendation of Meroni et al. [37] in a clinical practice guide, which does not indicate LLLT in individuals with chronic low back pain. However, Glazov et al. [38], in a meta-analysis indicate the use of LLLT with high doses in individuals with shorter pain durations, and in these cases there was moderate evidence of effectiveness, but still indicated the need for more blind studies.

One of the limitations of the present study is the lack of blindness for therapists, which is suggested for future studies. The small size of the studied population sample, which comprised only young, female university students, is also highlighted. Analyses with other populations are also necessary, for example, in athletes, because although there were three volunteers in each group who regularly performed physical exercises, none of them performed at a competitive level. The analysis of therapeutic associations with exercise protocols and longer treatment and follow-up periods is also suggested.

\section{CONCLUSION}

The use of cluster in young people with chronic non-specific lower back pain was ineffective for the relief of painful symptoms, nor did it promote a decrease in the repercussion reoccurence of lower back pain in the performance of daily life activities.

\section{Conflict of interest}

The authors declare they have no conflict of interest.

\section{Disclosure statement}

None of the authors have any financial interest or received any financial benefit from the research.

\section{REFERENCES}

1. Almeida DC, Kraychete DC. Low back pain - a diagnostic approach. Rev Dor. 2017; 18(2): 173-7.

2. Çinar-Medeni Ö, Elbasan B, Duzgun I. Low back pain prevalence in healthcare professionals and identification of factors affecting low back pain. J Back Musculoskelet Rehabil. 2017; 30(3): 451-9.

3. Pires RAM, Dumas FVL. Lombalgia: revisão de conceitos e métodos de tratamentos. Univ Ciências da Saúde. 2009 Jul 23; 6(2): 159-68.

4. Vlaeyen JWS, Maher CG, Wiech K, Zundert J Van, Meloto CB, Diatchenko L, et al. Low back pain. Nat Rev Dis Prim. 2018; 4(1): 52.

5. Helfenstein Junior M, Goldenfum MA, Siena C. Occupational low back pain. Rev Assoc Med Bras. 2010; 56(5): 583-9.

6. Lizier DT, Perez MV, Sakata RK. Exercícios para tratamento de lombalgia inespecífica. Rev Bras Anestesiol. 2012; 62(6): 838-46.

7. Maher C, Underwood M, Buchbinder R. Non-specific low back pain. Lancet. 2017; 389(10070): 736-47.

8. Kamel DM, Abdel NA, Tantawy SA. Efficacy of lumbar mobilization on postpartum low back pain in Egyptian females: A randomized control trial. J Back Musculoskelet Rehabil. 2016; 29(1): 55-63.

9. Coulter ID, Crawford C, Hurwitz EL, Vernon H, Khorsan R, Suttorp Booth $\mathrm{M}$, et al. Manipulation and mobilization for treating chronic low back pain: a systematic review and meta-analysis. Spine J. 2018; 18(5): 866-79.

10. Endaml1 D, Bayramlar K, Turhan B. Investigation of fascial treatment effectiveness on pain, flexibility, functional level, and kinesiophobia in patients with chronic low back pain. Physiother Q. 2019; 27(3): 1-5.

11. Tantawy SA, Kamel DM, Abdelbasset WK, Nambi G. A randomized controlled trial investigating the impact of interferential therapy on pain, range of motion and quality of life in patients with chronic nonspecific low back pain. Arch Balk Med Union. 2020; 55(1): 47-54.

12. Rubira APFDA, Rubira MC, Rubira LDA, Comachio J, Magalhães MO, Marques AP. Comparison of the effects of low-level laser and pulsed and continuous ultrasound on pain and physical disability in chronic non-specific low back pain: A randomized controlled clinical trial. Adv Rheumatol. 2019; 59(1): 57.

13. Huang Z, Ma J, Chen J, Shen B, Pei F, Kraus VB. The effectiveness of lowlevel laser therapy for nonspecific chronic low back pain: a systematic review and meta-analysis. Arthritis Res Ther. 2015; 17: 360.

14. Ferraresi C, Huang Y-Y, Hamblin MR. Photobiomodulation in human muscle tissue: an advantage in sports performance? J Biophotonics. 2016; 9(11-12): 1273-99.

15. Siqueira CPCM, Toginho Filho DDO, Lima FM de, Silva FP, Durante H, Dias IFL, et al. Efeitos biológicos da luz: aplicação de terapia de baixa potência empregando LEDs (Light Emitting Diode) na cicatrização da úlcera venosa: relato de caso. Semin Ciências Biológicas e da Saúde. 2009; 30(1): 37.

16. Tsai SR, Hamblin MR. Biological effects and medical applications of infrared radiation. J Photochem Photobiol B Biol. 2017; 170: 197-207.

17. Ezzati K, Fekrazad R, Raoufi Z. The effects of photobiomodulation therapy on post-surgical pain. J Lasers Med Sci. 2019; 10(2): 79-85.

18. Barez MM, Tajziehchi M, Heidari MH, Bushehri A, Moayer F, Mansouri $\mathrm{N}$, et al. Stimulation effect of low level laser therapy on sciatic nerve regeneration in rat. J Lasers Med Sci. 2017; 8(Suppl 1): S32-7.

19. Alves ACA, De Carvalho PDTC, Parente M, Xavier M, Frigo L, Aimbire F, et al. Low-level laser therapy in different stages of rheumatoid arthritis: A histological study. Lasers Med Sci. 2013; 28(2): 529-36.

20. Mansourian A, Pourshahidi S, Sadrzadeh-Afshar M-S, Ebrahimi H. A comparative study of low-level laser therapy and transcutaneous electrical nerve stimulation as an adjunct to pharmaceutical therapy for myofascial pain dysfunction syndrome: a randomized clinical trial. Front Dent. 2019 Dec 24; 16(4): 256-64.

21. Santos CM dos, Rocha RB da, Hazime FA, Cardoso VS. A systematic review and meta-analysis of the effects of low-level laser therapy in the treatment of diabetic foot ulcers. Int J Low Extrem Wounds [Internet]. 2020 May 12; 153473462091443. Available from: http://journals.sagepub. com/doi/10.1177/1534734620914439 
22. Cheung WKW, Wu IXY, Sit RWS, Ho RST, Wong CHL, Wong SYS, et al. Low-level laser therapy for carpal tunnel syndrome: systematic review and network meta-analysis. Physiotherapy [Internet]. $2020 \mathrm{Mar}$ 106: 24-35. Available from: https://linkinghub.elsevier.com/retrieve/ pii/S003194061930077X

23. Campos GRS, de Moura KMB, Barbosa AM, Zamuner LF, NadurAndrade N, Dale CS, et al. Light emitting diode (LED) therapy reduces local pathological changes induced by Bothrops asper snake venom. Toxicon. 2018; 152: 95-102.

24. Al-Quisi AF, Al-Anee AM, AL-jumaily HA, Bahr EF, Finjan DA. Efficacy of the LED red light therapy in the treatment of temporomandibular disorders: double blind randomized controlled trial. Pain Res Treat [Internet]. 2019 May 7; 2019: 8578703. Available from: https://www. hindawi.com/journals/prt/2019/8578703/

25. Gabel CP, Petrie SR, Mischoulon D, Hamblin MR, Yeung A, Sangermano $\mathrm{L}$, et al. A case control series for the effect of photobiomodulation in patients with low back pain and concurrent depression. Laser Ther. 2018; 27(3): 167-73.

26. Taradaj J, Rajfur K, Shay B, Rajfur J, Ptaszkowski K, Walewicz K, et al. Photobiomodulation using high-or low-level laser irradiations in patients with lumbar disc degenerative changes: disappointing outcomes and remarks. Clin Interv Aging. 2018; 13: 1445-55.

27. Tantawy SA, Abdelbasset WK, Kamel DM, Alrawaili SM, Alsubaie SF. Laser photobiomodulation is more effective than ultrasound therapy in patients with chronic nonspecific low back pain: a comparative study. Lasers Med Sci. 2019; 34(4): 793-800.

28. Melzack R. The McGill pain questionnaire. From description to measurment. Anesthesiology. 2005; 103(1): 199-202.
29. Sardá Júnior JJ, Nicholas MK, Pimenta CA de M, Asghari A, Thieme AL. Validation of the Roland Morris Disability Questionnaire for general pain. Rev Dor. 2010; 11(1): 28-36.

30. Falavigna A, Teles AR, De Braga GL, Barazzetti DO, Lazzaretti L, Tregnago AC. Instrumentos de avaliação clínica e funcional em cirurgia da coluna vertebral. Coluna/Columna. 2011; 10(1): 62-7.

31. Hedges L V. Effect sizes in cluster-randomized designs. J Educ Behav Stat. 2007; 32(4): 341-70.

32. Sullivan GM, Feinn R. Using effect size-or why the $\mathrm{P}$ value is not enough. J Grad Med Educ. 2012; 4(3): 279-82.

33. Silva JA da, Ribeiro-Filho NP. A dor como um problema psicofísico. Rev Dor. 2011; 12(2): 138-51.

34. Požgain I, Požgain Z, Degmečić D. Placebo and nocebo effect: A minireview. Psychiatr Danub. 2014; 26(2): 100-7.

35. Brody H. Meaning and an overview of the placebo effect. Perspect Biol Med. 2018; 61(3): 353-60.

36. Damien J, Colloca L, Bellei-Rodriguez C-É, Marchand S. Pain modulation: from conditioned pain modulation to placebo and nocebo effects in experimental and clinical pain. Int Rev Neurobiol. 2018; 139: 255-96.

37. Meroni R, Piscitelli D, Ravasio C, Vanti C, Bertozzi L, De Vito G, et al. Evidence for managing chronic low back pain in primary care: a review of recommendations from high-quality clinical practice guidelines. Disabil Rehabil. 2019; 0(0): Epub ahead of print.

38. Glazov G, Yelland M, Emery J. Low-level laser therapy for chronic nonspecific low back pain: a meta-analysis of randomised controlled trials. Acupunct Med. 2016 Oct 12; 34(5): 328-41. 